\title{
Breast Core-Needle Biopsy in a Large Tertiary Oncologic Centre-1-Year Experience after the Introduction of the Method
}

\author{
Zoran Brnić, Maja Marinkić*, Saša Schmidt, Ivo Pedišić, Karolina Bolanča-Čulo \\ Univeristy Hospital Sisters of Charity, Zagreb, Croatia \\ Email: *maja.marinkic@gmail.com
}

How to cite this paper: Brnić, Z., Marinkić, M., Schmidt, S., Pedišić, I. and BolančaČulo, K. (2016) Breast Core-Needle Biopsy in a Large Tertiary Oncologic Centre-1Year Experience after the Introduction of the Method. International Journal of Clinical Medicine, 7, 690-697.

http://dx.doi.org/10.4236/ijcm.2016.710075

Received: August 10, 2016

Accepted: October 24, 2016

Published: October 27, 2016

Copyright $\odot 2016$ by authors and Scientific Research Publishing Inc. This work is licensed under the Creative Commons Attribution International License (CC BY 4.0).

http://creativecommons.org/licenses/by/4.0/

(c) (i) Open Access

\section{Abstract}

Ultrasound (US)-guided core-needle biopsy (CNB) is currently the procedure of choice for work-up of suspicious breast lesion. It is mainly used for evaluation of suspicious breast lesions categorized as BI-RADS 4 and 5 (Breast Imaging-Reporting and Data System). The conducted study included 56 female patients with detected suspicious breast leasions, and they underwent US-guided CNB during 1-year period with the aim to investigate the value of US-guided CNB of the breast in a tertiarylevel large-volume oncological centre setting with respect of indications, technical adequacy and safety. 2 patients who entered the study were previously diagnosed as BIRADS 2, 3 patients as BIRADS 3,18 patients as BIRADS 4 and 33 patients as BIRADS 5. In 14 patients with BC (breast cancer), both FNA (fine-needle aspiration) and CNB were performed, and the malignancy was accurately diagnosed by cytology in 9 patients, confirmed by subsequent CNB in all of them. ADH (atypical ductal hyperplasia) was initialy diagnosed by FNA in 5 patients, and in 2 of them, BC was initialy missed by FNA, but deteced by CNB. As it is known, the cytology has lower sensitivity for detection of $\mathrm{BC}$ than hystology, with false-negative rate ranging from $2.5 \%$ to $17.9 \%$. In our material, $18.7 \%$ of carcinomas were initialy left undetected by FNAC, and subsequently confirmed by CNB. All confirmed carcinomas were correctly suspected on imaging, and categorized as BI-RADS 4 or 5, while all BI-RADS 2 and 3 findings were confirmed as benign on hystology. False-positive rate of imaging was $8 \%$. An average number of 4 tissue cores (range: 2 - 7) was taken in our experience if good quality of the first 3 core was achieved, and there was no consistent reason to proceed with sampling.

\section{Keywords}

Breast Cancer, US-Guided Core Needle Biopsy (CNB), Suspicious Breast Lesion, Tissue Core 


\section{Introduction}

Breast cancer $(\mathrm{BC})$ is one of the most common malignant tumors and an important cause of cancer-related deaths among women. Mammography (MG) is still considered to be the best screening test for $\mathrm{BC}$, with breast ultrasound (US) as the most appropriate complementary imaging modality [1] [2]. First described by Parker et al. in the early 1990s, US (ultrasound)-guided core-needle biopsy (CNB) is currently the most accurate method of tissue-sampling, and is the procedure of choice for work-up of US-detected suspicious breast lesion [3].

$\mathrm{CNB}$ is recognized as a reliable alternative to surgical biopsy for obtaining histologic diagnosis, commoly used for evaluation of suspicious breast lesions categorized as BI-RADS 4 and 5 (Breast Imaging-Reporting and Data System) [4] [5], valuable also in cases of undeterminate or probably benign lesions [6] [7] [8]. US-guided CNB has high sensitivity (97.5\%) in the detection of BC, and many advantages such as high safety due to real-time needle guidance and lack of radiation, possibility of evaluation of tumor grade and receptors, good patient comfort, wide availability, acceptable time consumption and more than fourfold lower costs than surgical biopsy in Croatia (official health service price-list, Croatian Health Insurance Office, 2015). However, an important limitation includes unability to biopsy lesions not clearly detectable by US such as microcalcifications and architectural distortions. Such lesions should be identified and targeted either stereotactically or by use of MRI, in order to avoid a false negative outcomes [3] [7]-[13].

US-guided CNB is a well-established procedure only in large clinical centres in Croatia, while in many mid-size and smaller county hospitals, the method is yet not accepted, mainly due to the lack of qualified personel. Retrospective study performed in the largest Croatian hospital centre, which included imaging-histological concordance analysis, revealed high accuracy, low percentage of false-negative results and high safety of the procedure [14].

Our study aimed to investigate the value of US-guided CNB of the breast in a tertiarylevel large-volume oncological centre setting with respect of indications, technical adequacy and safety.

\section{Materials and Methods}

The study included 56 female patients with detected suspicious breast leasions, who underwent US-guided CNB during 1-year period (September 2014-October 2015). Breast CNB was performed as part of the tripple assessment routinely applied in the institution. In selected cases the fine-needle aspiration (FNA) with cytological analysis was done prior to CNB, particularly in patients with clinical suspicion of neoplasm but without imaging findings suggestive of $\mathrm{BC}$, and patients with probably benign imaging findings (BIRADS 3) and no evidence of increased risk for BC. Informed consent before the procedure was mandatory for every patient.

US-guided CNB of the breast-the procedure: The women were placed in the supine position with ipsilateral upper limb resting behind their heads. After the patients' skin 
was prepped and the target area covered with sterile drapes, the radiologist performed the puncture using the "freehand technique", holding the transducter with one hand while identifying the target lesion and manipulating the spring-loaded CNB device with the other hand. Under US-guidance $2-5 \mathrm{~mL}$ of lidocaine was injected along the presumed needle pathway. A small skin nick was made at the needle entry site, and the biopsy needle was inserted. Disposable HTC device (HUNTER Automatic guillottine system, Tsunami Medical, Italy) with 10 or $15 \mathrm{~cm}$ long $14-\mathrm{G}$ needle with $22-\mathrm{mm}$ throw was used for all procedures. The oblique approaching pathway of the needle, with consequent parallel needle position to the chest wall during firing was preferred in order to provide good visualisation of the needle and to assure the best safety. After the CNB device was fired, the needle tip was identified inside the mass, and image was recorded to document the correct targeting. The adequacy of tissue samples was visually checked for integrity and colour. Each specimen was put into the 10\%-buffered formaldehyde solution, checked for floating (predominantly fat tissue) or sinking (presumably glandular and/or fibrous tissue), and sent to pathology for analysis.

The referring diagnoses, distribution of BI-RADS categories, reasons for US-guided $\mathrm{CNB}$, and diagnostic outcome after tissue sampling were shown in percentages and discussed. The length of tissue cores was measured by ruler. The number of cores per procedure was analysed. The quality of tissue cores were visualy analysed for floating in the formaldechyde solution, integrity (fragmentation) and bloodiness. Pathologist's observations upon inadequacy of sampling material were considered.

\section{Results and Discussion}

Fifty-six patients (58.7 years, range 37 - 80, 48.2\% premenopausal) were included in our series. The patients were referred to our hospital by breast surgeons, oncologists or family doctors with the request to get breast CNB performed. No special preparation was proposed, except anticoagulants or aspirin withdrawal 3 days prior to procedure. Table 1 shows referring diagnoses from request forms for the patients which underwent USguided CNB. In the vast majority of cases the indication for CNB was based on clinical and/or radiological suspicion of breast malignancy. Relatively high proportion of referring diagnoses reflected disease non-confined to the breast (39/67, 58.2\%), while $46.4 \%$ (26/56) patients was assigned a simple clinical diagnose breast neoplasm, without any other specification. In $22 / 56$ (39.2\%) of women lymph node metastases were clinicaly suspicious (18 cases of axillary, and 4 cases of other regional lymphadenopathy). In 1 patient $\mathrm{CNB}$ was indicated after cytological detection of atypical ductal hyperplasia $(\mathrm{ADH})$ in fine-needle aspiration (FNA) material [15] [16].

The distribution of BI-RADS categories of patients underwent US-guided CNB was shown in Table 2. There was no patients assigned as BI-RADS 0 or 1 in our material, meaning that $\mathrm{CNB}$ was not done in patients with incomplete diagnostic work-up or in patient in which imaging was normal, even if clinical finding was suspicious. BIRADS 0 category requires either repeat of MG or further imaging study(ies), hence no CNB is indicated [4]. In our institution the patients without imaging findings suggestive of 
Table 1. Referring diagnoses assigned to patients submitted to US-guided CNB.

\begin{tabular}{ccc}
\hline Referring diagnosis & Number of patients & Comment/remark \\
\hline $\begin{array}{c}\text { Breast cancer (BC) } \\
\text { (without other specification) }\end{array}$ & 26 & 6 \\
Bilateral BC & 7 & \\
Inoperative/exulcerated BC & 1 & \\
Inflammatory BC & 18 & \\
BC with enlarged axillary nodes & 2 & \\
BC with enlarged neck nodes & 2 & Palpatory suspect, enlarging \\
BC with enlarged supraclavicular nodes & 2 & Palpatory suspect, atypical ductal \\
BC with distant metastases & 1 & hyperplasia detected by cytology \\
BC with infiltration of pleura & 1 & Some patients were assigned with \\
Fibroadenoma & 1 & more than one referring diagnose \\
Mastopathia & 67 & \\
Total number of diagnoses & &
\end{tabular}

Table 2. BI-RADS categories of patients underwent US-guided CNB: the highest US, MG or MR BI-RADS category was taken into account if more than one imaging modality were done prior to CNB.

\begin{tabular}{ccc}
\hline Imaging category & Number of patients & Comment/remark \\
\hline BIRADS 2 & 2 & Palpatory suspect \\
BIRADS 3 & 3 & \\
BIRADS 4 & 18 & \\
BIRADS 5 & 33 & \\
Total number of patients & 56 & \\
\hline
\end{tabular}

neoplasm, but with palpatory suspicion of malignancy undergo FNA as only primary sampling method. Two BI-RADS 2 patients with palpatory suspicious breast lump had equivocal FNA findings from other institution, and were biopsied following the request of other doctors, which thought that the findings were of limited accuracy. Very low proportion of BI-RADS 3 patients in our material $(3 / 56,5.4 \%)$ reflects the practice that patients with probably benign breast lesions are commonly submitted to US-guided FNA, and regular US follow-up in 6-months periods [5]. BI-RADS 5 is the most frequent category in our series $(33 / 56,58.9 \%)$ as clinicaly and radiologicaly clearly malignant or advanced breast neoplasms tend to cumulate in our specialized national oncology centre in which a wide spectrum of diagnostic and treatment options are readily available for patients with BC.

Reasons for US-guided CNB were specified in Table 3. Remarkable proportion of patients $(28 / 56,50 \%)$ were candidates for neoadjuvant therapy, and CNB is mandatory 
Table 3. Reasons for US-guided CNB.

\begin{tabular}{cc}
\hline Reasons for biopsy & Number of patients \\
Preoperative PHD & 24 \\
Neoadjuvant therapy planned & 28 \\
Other reasons & 4 \\
Total number of patients & 56 \\
\hline
\end{tabular}

for such patients as it enables proper choice of the best antineoplastic agent [17]. The category other reasons include inconclusive FNA findings and lesions suspected by MR detectable also by US.

In the subgroup of 14 patients with $\mathrm{BC}$ both FNA and $\mathrm{CNB}$ were performed, and the malignancy was accurately diagnosed by cytology in 9 patients, confirmed by subsequent $\mathrm{CNB}$ in all of them. ADH was initialy diagnosed by FNA in 5 patients, and in 2 of them BC initialy missed by FNAC was subsequently found at hystology. As it is known, the cytology has lower sensitivity for detection of BC than hystology, with false-negative rate ranging from $2.5 \%$ to $17.9 \%$. In our material $18.7 \%$ of carcinomas were initialy left undetected by FNAC, and subsequently confirmed by $\mathrm{CNB}$, which is not significantly different from the results in the literature [15] [16] [18].

Table 4 shows histological diagnoses obtained from CNB in comparison to imaging findings. As expected, the majority of tumors were invasive ductal carcinomas, and only 2 tumors of lobular origin were found. All carcinomas confirmed by hystology were correctly suspected on imaging, and categorized as BI-RADS 4 or 5. All BI-RADS 2 and 3 findings were confirmed as benign on hystology; these patients were proceeded to $\mathrm{CNB}$ because of palpatory suspicion for malignancy. False-positive rate of imaging was $8 \%$, as a result of 2 false-positive MRI findings and 2 false-positive MG findings.

With each CNB procedure, an average number of 4 tissue cores (range 2 - 7) were taken from different parts of the US-detectable lesion. The central, possibly necrotic areas of the tumor were consistently avoided from targeting. The length of tissue cores in our material ranged $19-23 \mathrm{~mm}$.

No cores obtained in our material was considered by pathologist as inadequate for hystological analysis, hence no re-biopsies were requested neither by pathologist nor by clinician. Other authors report up to $10 \%$ of re-biopsies in their material [14] [19] [20]. We observed fragmentation in $27 \%$ of cores, which did not compromised the value of CNB. First obtained tissue core was of the best quality in 49/56 (87.5\%) of cases, while subsequent cores were more or less blood, as the destruction of the breast architecture, and local haemorrhage occurs. The last tissue core was bloody and fragmentated in $33 / 56(58.9 \%)$ of procedures.

European guidelines are not too dogmatic about the number of cores, realizing that variablity can be accepted between cases and operators [21]. We think that even a single core may be sufficient for the diagnosis of a solid mass, if the radiologist is confident of sampling adequacy. If good quality of the first 3 core was achieved, there was no consistent reason to proceed with sampling in our experience. This may differ from the 
Table 4. Pathophysiological diagnoses (PHD) obtained from CNB in comparison to imaging findings.

\begin{tabular}{cccc}
\hline PHD & Number of patients & BI-RADS 4 or 5 & BI-RADS 2 or 3 \\
\hline Invasive ductal carcinoma & 44 & 44 & 0 \\
Lobular carcinoma in situ & 1 & 1 & 0 \\
Invasive lobular carcinoma & 1 & 1 & 0 \\
No tumor & 10 & $4^{*}$ & 6 \\
Total number of patients & 56 & 50 & 6
\end{tabular}

${ }^{*}$ MR BI-RADS 4 in 2 patients, MG BI-RADS 4 in 2 patients; ${ }^{* *}$ palpatory suspicious BI-RADS 2 in 3 patients, BI-RADS 3 in 3 patients.

opinion that larger core number is necessary [6] [22]. The higher the number the cores, the higher representativeness of the material in the sense of accurate targeting the lesion of interest. Hovewer, our patients had relatively large tumors, and no risk of off-target cores existed, hence even limited number of samples seemed to be acceptable. With small lesions, even more than 4 cores might be needed to surpass the risk of nonrepresentative targeting, which can compromise the procedure and cause the recall. Absolute care should be taken that first 2 - 3 cores were sampled from representative place in the breast, as the bleeding, especialy in loose breasts, can obscure precise targeting in the further course of the procedure.

Only $2.3 \%$ of tissue cores floated in formaldechyde solution, which meant that they could be predominantly fatty, hence unrepresentative for analysis. The cores from the lesions containing microcalcifications were not radiographed, as the detection of microcalcifications in the samples would not be critical for further work-up.

All patients tolerated the procedure well, with only one case of psychosomatic reaction (fainting, dizziness) and 2 patients experiencing moderate local breast pain. No significant complications related to the procedure were recorded. In one patient prolonged venous bleeding occured, treated with consistent compresion of the puncture site for 20 minutes. In one patient local anesthesia was not applied, as the patient informed the staff about severe anaphylactoid reaction 3 years ago, related to lidocaine injection prior to small surgical procedure. The patient agreed that CNB would be performed using only lidocaine skin spray, and experienced moderate but tolerable local pain in the breast.

Our study have some limitations: As the method is not yet generaly accepted in the region as a standard, the indication were set inconsistently in some cases, and the method is done less frequently than necessary because of lack of resources. This is a low-volume study intended primarily to describe the initial experience rather than profoundly examine the value of the procedure, which is already well investigated by many authors. The procedure was performed by three operators with different skill in the technique (1 highly, 2 moderately experienced) which may influence the quality of specimens and the safety. 


\section{Conclusion}

In conclusion, US-guided breast CNB is accurate, safe, and a well tollerable tissue sampling procedure which can be performed only with limited resources, and the results are valuable in the work-up of patients with suspicion of breast malignancy. The operator should adhere to basic interventional US safety standards, and take into account advantages and limitation of the method.

\section{References}

[1] Leconte, I., Feger, C., Galant, C., Berliere, M., Berg, B.V., D’Hoore, W., et al. (2003) Mammography and Subsequent Whole-Breast Sonography of Nonpalpable Breast Cancers: The Importance of Radiologic Breast Density. American Journal of Roentgenology, 180, 1675-1679. http://dx.doi.org/10.2214/ajr.180.6.1801675

[2] Kolib, T.M., Lichy, J. and Newhouse, J.H. (2002) Comparison of the Performance of Screening Mammography, Physical Examination, and Breast US and Evaluation of Factors That Influence Them: An Analysis of 27,825 Patient Evaluations. Radiology, 225, 165-175. http://dx.doi.org/10.1148/radiol.2251011667

[3] Parker, S.H., Jobe, W.E., Dennis, M.A., Stavros, A.T., Johnson, K.K., Yakes, W.F., et al. (1993) US-Guided Automated Large-Core Breast Biopsy. Radiology, 187, 507-511. http://dx.doi.org/10.1148/radiology.187.2.8475299

[4] Sickles, E.A., D’Orsi, C.J., Bassett, L.W., et al. (2013) ACR BI-RADS Mammography. In: ACR BI-RADS Atlas, Breast Imaging Reporting and Data System, 5th Edition, American College of Radiology, Reston, VA, 134-136.

[5] Mendelson, E.B., Böhm-Vélez, M., Berg, W.A., et al. (2013) ACR BI-RADS Ultrasound. In: ACR BI-RADS Atlas, Breast Imaging Reporting and Data System, 5th Edition, American College of Radiology, Reston, VA, 128-130.

[6] Pijnappel, R.M., van den Donk, M., Holland, R., Mali, W.P., Peterse, J.L., Hendriks, J.H., et al. (2004) Diagnostic Accuracy for Different Strategies of Image-Guided Breast Intervention in Cases of Nonpalpable Breast Lesions. British Journal of Cancer, 90, 595-600. http://dx.doi.org/10.1038/sj.bjc.6601559

[7] Parker, S.H., Burbank, F., Jackman, R.J., Aucreman, C.J., Cardenosa, G., Cink, T.M., et al. (2004) Percutaneous Large-Core Breast Biopsy: A Multi-Institutional Study. Radiology, 193, 359-364. http://dx.doi.org/10.1148/radiology.193.2.7972743

[8] Vargas, H.I., Vargas, M.P., Gonzalez, K.D., Venegas, R., Canet, M., Burla, M., et al. (2004) Diagnosis of Palpable Breast Masses: Ultrasound-Guided Large Core Biopsy in a Multidisciplinary Setting. Annals of Surgery, 70, 867-871.

[9] Liberman, L. (2000) Percutaneous Imaging-Guided Core Breast Biopsy: State of the Art at the Milennium. American Journal of Roentgenology, 174, 1191-1199. http://dx.doi.org/10.2214/ajr.174.5.1741191

[10] Liberman, L. (2002) Percutaneous Image-Guided Core Breast Biopsy. Radiologic Clinics of North America, 40, 483-500. http://dx.doi.org/10.1016/S0033-8389(01)00011-2

[11] Liberman, L., Feng, T.L., Dershaw, D.D., Morris, E.A. and Abramson, A.F. (1998) USGuided Core Breast Biopsy: Use and Cost-Effectiveness. Radiology, 208, 717-723. http://dx.doi.org/10.1148/radiology.208.3.9722851

[12] Dillon, M.F., Hill, A.D., Quinn, C.M, O’Dohrety, A. and McDermott, E.W. (2005) The Accuracy of Ultrasound, Stereotactic, and Clinical Core Biopsiesinth Diagnosis of Breast Cancer with an Analysis of False-Negative Cases. Annals of Surgery, 242, 701-707. 
http://dx.doi.org/10.1097/01.sla.0000186186.05971.e0

[13] Burkhardt, J.H. and Sunshine, J.H. (1992) Core-Needle and Surgical Breast Biopsy: Comparison of Three Methods of Assessing Cost. Radiology, 212, 181-188.

[14] Prutki, M., Stern-Padovan, R., Jakić-Razumović, J., Potocki, K., Badovinac-Crnjević, T. and Golubić, A.T. (2012) Ultrasound-Guided Breast Biopsy-A Retrospective Study and Literature Review. Lijec Vjesn, 134, 270-275.

[15] Willems, S.M., van Deurzen, C.H.M. and van Diest, P.J. (2012) Diagnosis of Breast Lesions: Fine-Needle Aspiration Cytology or Core Needle Biopsy? Journal of Clinical Pathology, 65, 287-292. http://dx.doi.org/10.1136/jclinpath-2011-200410

[16] Kocjan, G., Bourgain, C., Fassina, A., Hagmar, B., Herbert, A. and Kapila, K. (2008) The Role of Breast FNAC in Diagnosis and Clinical Management: A Survey of Current Practice. Cytopathology, 19, 271-278. http://dx.doi.org/10.1111/j.1365-2303.2008.00610.x

[17] Rakha, E.A. and Ellis, I.O. (2007) An Overview of Assessment of Prognostic and Predictive Factors in Breast Cancer Needle Core Biopsy Specimens. Journal of Clinical Pathology, 60, 1300-1306. http://dx.doi.org/10.1136/jcp.2006.045377

[18] Chaiwun, B. and Thorner, P. (2007) Fine Needle Aspiration for Evaluation of Breast Masses. Curr Opin Obstet Gynecol, 19, 48-55. http://dx.doi.org/10.1097/GCO.0b013e328011f9ae

[19] Youk, J.H., Kim, E.K., Kim, M.J. and Oh, K.K. (2007) Missed Breast Cancers at US-Guided Core Needle Biopsy: How to Reduce Them. Radiographics, 27, 79-94. http://dx.doi.org/10.1148/rg.271065029

[20] Dahmer Rocha, R., Reis Pinto, R., Paes Barreto, D., Tavares, A. and Aires Goncavles, C.S. (2013) Step-by-Step of Ultrasound Guided Core-Needle Biopsy of the Breast: Review and Technique. Radiologia Brasileira, 46, 234-241. http://dx.doi.org/10.1590/S0100-39842013000400010

[21] Zhang, Y.J., Wei, L., Zheng, Y.Q. and Li, X.R. (2013) Status Quo and Development Trend of Breast Biopsy Technology. Gland Surgery, 2, 15-24.

[22] Tamaki, K., Sasano, H., Ishida, T., Miyashita, M., Takeda, M., Amari, M., et al. (2010) Comparison of Core Needle Biopsy (CNB) and Surgical Specimens for Accurate Preoperative Evaluation of ER, PgR and HER2 Status of Breast Cancer Patients. Cancer Science, 101, 2074-2079. http://dx.doi.org/10.1111/j.1349-7006.2010.01630.x

\section{Submit or recommend next manuscript to SCIRP and we will provide best service} for you:

Accepting pre-submission inquiries through Email, Facebook, LinkedIn, Twitter, etc. A wide selection of journals (inclusive of 9 subjects, more than 200 journals)

Providing 24-hour high-quality service

User-friendly online submission system

Fair and swift peer-review system

Efficient typesetting and proofreading procedure

Display of the result of downloads and visits, as well as the number of cited articles Maximum dissemination of your research work

Submit your manuscript at: http://papersubmission.scirp.org/

Or contact ijcm@scirp.org 